\title{
Attention and Working Memory in Adolescents with Autism Spectrum Disorder : A Functional MRI Study
}

Rahko, Jukka S.

2016-06

Rahko , J S , Vuontela , V A , Carlson, S , Nikkinen , J , Hurtig , T M , Kuusikko-Gauffin , S , Mattila, M-L, Jussila, K K, Remes , J J , Jansson-Verkasalo, E M , Aronen, E T , Pauls , D L , Ebeling , H E , Tervonen , O , Moilanen , I K \& Kiviniemi , V J 2016 , ' Attention and Working Memory in Adolescents with Autism Spectrum Disorder : A Functional MRI Study ' , Child Psychiatry and Human Development, vol. 47 , no. 3 , pp. 503-517 . https://doi.org/10.1007/s10578-015-0583-C

http://hdl.handle.net/10138/224006

https://doi.org/10.1007/s10578-015-0583-6

publishedVersion

Downloaded from Helda, University of Helsinki institutional repository.

This is an electronic reprint of the original article.

This reprint may differ from the original in pagination and typographic detail.

Please cite the original version. 


\title{
Attention and Working Memory in Adolescents with Autism Spectrum Disorder: A Functional MRI Study
}

\author{
Jukka S. Rahko' ${ }^{1}$ Virve A. Vuontela ${ }^{2,3}$ - Synnöve Carlson ${ }^{2,3} \cdot$ Juha Nikkinen ${ }^{4}$. \\ Tuula M. Hurtig ${ }^{1,5}$ - Sanna Kuusikko-Gauffin ${ }^{1}$ - Marja-Leena Mattila ${ }^{1}$ • \\ Katja K. Jussila ${ }^{1}$ Jukka J. Remes ${ }^{4}$ - Eira M. Jansson-Verkasalo ${ }^{6,9}$ \\ Eeva T. Aronen ${ }^{7}$ David L. Pauls ${ }^{8} \cdot$ Hanna E. Ebeling ${ }^{1} \cdot$ Osmo Tervonen $^{4}$. \\ Irma K. Moilanen ${ }^{1} \cdot$ Vesa J. Kiviniemi ${ }^{4}$
}

Published online: 1 September 2015

(C) Springer Science+Business Media New York 2015

\begin{abstract}
The present study examined attention and memory load-dependent differences in the brain activation and deactivation patterns between adolescents with autism spectrum disorders (ASDs) and typically developing (TD) controls using functional magnetic resonance imaging. Attentional (0-back) and working memory (WM; 2-back) processing and load differences ( 0 vs. 2-back) were analysed. WM-related areas activated and default mode network deactivated normally in ASDs as a function of task load. ASDs performed the attentional 0-back task similarly to TD
\end{abstract}

Jukka S. Rahko

jrahko@me.com; jukka.rahko@ppshp.fi;

Jukka.Rahko@oulu.fi

Virve A. Vuontela

vvuontel@mappi.helsinki.fi

Synnöve Carlson

syncarls@cc.helsinki.fi

Juha Nikkinen

Juha.Nikkinen@ppshp.fi

Tuula M. Hurtig

tuula.hurtig@oulu.fi

Sanna Kuusikko-Gauffin

sanna.kuusikkogauffin@gmail.com

Marja-Leena Mattila

marja-leena.mattila@fimnet.fi

Katja K. Jussila

katja.jussila@gmail.com

Jukka J. Remes

jukka.remes@oulu.fi

Eira M. Jansson-Verkasalo

eira.jansson-verkasalo@utu.fi

Eeva T. Aronen

eeva.aronen@helsinki.fi controls but showed increased deactivation in cerebellum and right temporal cortical areas and weaker activation in other cerebellar areas. Increasing task load resulted in multiple responses in ASDs compared to TD and in inadequate modulation of brain activity in right insula, primary somatosensory, motor and auditory cortices. The changes during attentional task may reflect compensatory mechanisms enabling normal behavioral performance. The inadequate memory load-dependent modulation of activity suggests diminished compensatory potential in ASD.

David L. Pauls

dpauls@pngu.mgh.harvard.edu

Hanna E. Ebeling

hanna.ebeling@ppshp.fi; hanna.ebeling@oulu.fi

Osmo Tervonen

osmo.tervonen@ppshp.fi

Irma K. Moilanen

irma.moilanen@oulu.fi

Vesa J. Kiviniemi

vesa.kiviniemi@oulu.fi

1 PEDEGO Research Unit, Child Psychiatry, University Hospital of Oulu, University of Oulu, P.O. Box 5000, 90014 Oulu, Finland

2 Brain Research Unit, O. V. Lounasmaa Laboratory, Department of Neuroscience and Biomedical Engineering, Aalto University School of Science, Espoo, Finland

3 Neuroscience Unit, Department of Physiology, Faculty of Medicine, Institute of Biomedicine/Physiology, University of Helsinki, Helsinki, Finland

4 Department of Diagnostic Radiology, University and University Hospital of Oulu, P.O. Box 50, 90029 Oulu, Finland 
Keywords Autism spectrum disorder · Attention .

Default mode network · Working memory · Visuospatial

\begin{tabular}{|c|c|}
\hline \multicolumn{2}{|c|}{ Abbreviations } \\
\hline ACC & Anterior cinculate cortex \\
\hline ADI-R & Autism diagnostic interview-revised \\
\hline ADOS & Autism diagnostic observation schedule \\
\hline ANOVA & Analysis of variance \\
\hline ASD & Autism spectrum disorder \\
\hline ASSQ & Autism Spectrum Screening Questionnaire \\
\hline BET & Brain extraction tool \\
\hline BOLD & Blood oxygenation level-dependent \\
\hline DMN & Default mode network \\
\hline DSM-5 & $\begin{array}{l}\text { Diagnostic and statistical manual of mental } \\
\text { disorders }\end{array}$ \\
\hline DSM-IV-TR & $\begin{array}{l}\text { Diagnostic and statistical manual of mental } \\
\text { disorders }\end{array}$ \\
\hline FLIRT & $\begin{array}{l}\text { FMRIB's (Functional MRI of the Brain) } \\
\text { linear image registration tool }\end{array}$ \\
\hline FMRI & Functional magnetic resonance imaging \\
\hline K-SADS-PL & $\begin{array}{l}\text { Schedule for affective disorders and } \\
\text { schizophrenia for school-age children- } \\
\text { present and lifetime version }\end{array}$ \\
\hline MNI & Montreal neurological institute \\
\hline PCC & Posterior cingulate cortex \\
\hline $\mathrm{PFC}$ & Prefrontal cortex \\
\hline TD & Typically developing \\
\hline WISC-III & $\begin{array}{l}\text { Wechsler Intelligence Scale for Children- } \\
\text { third version }\end{array}$ \\
\hline WM & Working memory \\
\hline
\end{tabular}

\section{Introduction}

Autism Spectrum Disorder (ASD) is a set of complex developmental disabilities defined by impairments in social interaction and social communication, and by the presence of restricted repetitive and stereotyped behaviors, interests and

5 Institute of Health Sciences, Clinic of Child Psychiatry, University and University Hospital of Oulu, University of Oulu, P.O. Box 5000, 90014 Oulu, Finland

6 Neurocognitive Unit, University and University Hospital of Oulu, Oulu, Finland

7 Children's Hospital, Child Psychiatry, Helsinki University Central Hospital, University of Helsinki, Biomedicum 2, Tukholmankatu 8 C 613, Helsinki 00290, Finland

8 Psychiatric and Neurodevelopmental Genetics Unit, Center for Human Genetic Research, Massachusetts General Hospital/Harvard Medical School, 185 Cambridge Street, Boston, MA 02114, USA

9 Department of Behavioral Sciences and Philosophy, Centre for Cognitive Neuroscience (CCN), University of Turku, Assistentinkatu 7, Turku 20017, Finland activities [2, 3, 101]. The social-communication deficits may reflect decreased motivation to engage in social behaviors in early childhood [25]. While deficits in social interaction are often accorded with a central or even causal role in the disorder [22, 23, 41, 80], subjects with ASD have also been reported to have alterations in cognitive processes at different levels [27]. These include perception and attention $[10,11]$ and higherlevel cognitive processes such as face memory [37], executive functions [48], and the mirror neuron system [21, 75].

\section{Higher-Level Cognitive Processes}

Executive functions have traditionally been linked to frontal lobe [65, 81], although this relation is not necessarily a direct one [1]. Moreover, involvement of the parietal cortex [24, 87] has recently become evident. As deficit in executive functions have been associated with some of the everyday social behaviors seen in individuals with ASD [34, 70], there could be also deficit in their brain areas or connections involved with executive functions. For example, Koshino et al. [50] found reduced functional connectivity between the left and right fusiform areas and left frontal regions during facial working memory (WM) task performance in subjects with autism.

\section{Attentional Processes}

Attention deficiency is a common co-morbidity in ASD [17] and recently renewed DSM-5 allows comorbid diagnose of attentional deficit hyperactivity disorder (ADHD) with ASD $[2,64]$. The prevalence of a ADHD as a lifetime diagnosis is $44 \%$ in ASD subjects [62] versus 7-8\% in community based [84]. Previous study of Christakou et al. [17] have shown that maintaining sustained attention in ASD and ADHD reduced significantly activation in bilateral striato-thalamic regions, left dorsolateral prefrontal cortex (DLPFC) and increased the activation in precuneus relative to typically developing (TD) controls. They also noted that default mode suppression was a shared deficit in ASD and ADHD [17].

Attentional processes are closely intertwined with memory functions with overlapping neural circuits $[6,53$, 95]. Working memory (WM) tasks activate a frontoparietal network of brain areas $[6,53,95]$, that has also been related to spatial attention [19]. Adolescents and young adults with autism have deficits in spatial WM [66, 76, 77]. Also the brain networks subserving these processes show overlap in some areas of the underlying neural circuitry $[6,53,95]$.

\section{Working Memory (WM)}

Subjects with ASD usually have typical or enhanced visuospatial abilities [16] but show dysfunction in WM [66, 
76-78]. Adolescents with ASD may have intact visual object memory and enhanced visual object recognition [23, 24, 36, 52]. Adults with ASD have been shown to have an abnormal WM-related pattern of activation in the dorsolateral prefrontal cortex (PFC) and dorsal anterior cingulate cortex (ACC) [27], however, in younger individuals with ASD it has not been studied thus, the role of maturation is unknown.

\section{Brain Deactivation}

Functional magnetic resonance imaging (fMRI) researchers have fairly recently started focusing more on decreased blood oxygen level dependent (BOLD) signal during cognitive task performance [32]. A set of brain areas called the default mode network (DMN) is most active in resting state and becomes deactivated, i.e., the BOLD signal reduces, during tasks requiring attention, including working memory or WM tasks [32]. Increasing task difficulty is known to increase the suppression of the BOLD signal $[82,89]$. The task-induced deactivation within the DMN has been shown to be altered in ASD in the anterior cingulate cortex (ACC) $[17,47]$. Recently, it was shown that also the spatial pattern of deactivation may alter as a function of task load in healthy subjects; areas outside the DMN may also deactivate when task demands increase [35].

\section{Rationale and Hypothesis}

Our aim was to differentiate the roles of attention and memory functions during WM tasks performed by adolescents with ASD. We used fMRI to investigate brain activity in subjects performing an n-back visual task paradigm, where the memory task load were modulated parametrically by changing only the instructions while maintaining all other features of the task constant $[14,18]$. Successful performance of this task requires continuous attentional monitoring, updating and recalling of the memorized information [71].

In our study, the 0-back task that involves attentional processing [71], was used to locate the brain regions displaying attention-related activation and deactivation. The 2-back task that places high demands on the key processes within WM was used to detect memory-load dependent signal changes [13-15]. The 2-back task can also be used in probing the load-dependency of the DMN deactivation in subject with ASD, since TD children have shown memory load-dependent deactivation in cortical areas corresponding to the DMN in adults [94].

We hypothesized that attention related functions (rather than WM related) may be altered in subjects with ASD due to the high prevalence of attentional difficulties reported in ASD. Moreover, we hypothesized that alterations in the memory load-dependent brain deactivation patterns could be altered in ASD. In order to test our hypothesis we mapped the neuronal networks that support attention and WM in adolescents with ASDs and in TD controls. We investigated both low load attentional processing (0-back) and higher load WM processing (2-back) in contrast to fixation baseline and signal changes between the loads ( 0 vs. 2-back). We investigated differences in brain activation and deactivation patterns related to attention and WM task performance between adolescents with ASD and TD controls.

\section{Materials and Methods}

\section{Study Population}

Thirty high-functioning (full-scale IQ [FSIQ] $>75$ ) adolescents with ASD were gathered from two, partly overlapping studies: (1) A community-based study conducted between 2000 and 2005 [60, 63, 64] and from (2) a clinicbased study conducted in 2003 [51, 61, 98]. Thirty age- and gender-matched TD controls were recruited from mainstream schools in Oulu [38, 51]. We did not measure the IQ of TD adolescents. However, they all attended mainstream education and their mean score for school performance was 8.24, range 7.00-9.75 (Convert table to US school system: $10=\mathrm{A}, 9=\mathrm{B}, 8=\mathrm{C}, 7=\mathrm{D})$. In Finland, pupils with normal intelligence attend mainstream education. All participants and their parents gave written informed consent, and the study was approved by the Ethics Committee of the Northern Ostrobothnia Hospital District area, Finland.

Of the 30 subjects with ASD, two were excluded: One subject refused to undergo scanning after the first visit because of the high noise level, and one fMRI dataset was lost due to computer storage error. Of the 30 control subjects, eight were excluded: (1) Two datasets were discarded due to bad data quality, (2) Three control subjects did not perform the n-back tasks, and (3) One control had teeth braces, and due to the resulting imaging artifacts, scanning was aborted, (4) Two controls were discarded due to elevated ASD symptoms measured with the Autism Spectrum Screening Questionnaire (ASSQ score >7) [64].

Finally, 28 subjects (FSIQ $=94.4$, range 76-155); 8 females, 20 males, mean age 14.6 years, range 11.4-17.6), 20 with Asperger syndrome (AS) and 8 with high-functioning autism (HFA) based on the DSM-IV-TR criteria [3, 4] and 22 TD controls ( 8 females, 14 males, mean age 14.4 years, range 11.8-17.3) were included in our fMRI study. Subjects with ASD and controls had normal or corrected-to-normal vision. The ASD group consisted predominantly of right-handed subjects $(\mathrm{n}=25)$, with three left-handed subjects, as determined by clinical 
observation and parental reports. The control group was also predominantly right-handed $(\mathrm{n}=20)$ and two lefthanded as determined by self-report. The subjects with ASD and their controls were not under any medication and they did not have Tourette's disorder or severe hyperkinesia in order to avoid confounding factors.

\section{Diagnosis of ASDs in the Community-Based Sample}

In the community-based study, 4422 (participation rate $81 \%)$ 8-year-old children born in 1992 were screened with the ASSQ [30, 42] and 110 (participation rate $88 \%$ ) children who screened positive in the ASSQ were examined in-person with clinical assessments that included the Autism Diagnostic Interview-Revised [57], the Autism Diagnostic Observation Schedule-module 3 [58], the Schedule for Affective Disorders and Schizophrenia for School-Age Children [44], and the Wechsler Intelligence Scale for Children-Third revision [97]. Additionally, school observations for 24 screened were undertaken, because more information was considered to be necessary. Medical records were reviewed. The ADI-R and ADOS were not used to make diagnostic classifications (i.e., the diagnostic algorithms were not used). Instead, these instruments were used to obtain structured information from parents and for semi-structured observation of a child. Based on consensus, clinical best estimate according to DSM-IV-TR [2] was used to make the diagnosis of ASD.

\section{Diagnosis of ASDs in the Clinic-Based Sample}

The target population included all registered high-functioning children (FSIQ $\geq 80$ ) and adolescents with AS or AS traits (i.e., features of AS or autism) or AS suspected at Oulu University Hospital prior to 2003. All outpatients had been diagnosed in the University Hospital of Oulu based on the ICD-10 criteria [101], supervised by a child psychiatrist or a child neurologist. Clinical diagnoses had then been reevaluated in-person clinical assessments including the ASSQ, ADI-R, ADOS (module 3), and K-SADS-PL. Medical records were reviewed. The ADI-R and ADOS were not used to make diagnostic classifications (i.e., the diagnostic algorithms were not used). Instead, these instruments were used to obtain structured information from parents and for semi-structured observation of a child. A clinical best estimate according to DSM-IV-TR [2] was used to make the diagnosis of ASD. Severe developmental disorders (e.g., dysphasia, Fragile-X).

\section{The fMRI Procedure}

In this study, the imaging procedure was identical to the procedure used in our previous studies $[9,72,74,75]$. All subjects with ASDs and controls had normal or correctedto-normal vision with MRI-compatible plastic spectacles. Prior to the experiment all subjects watched an introductory video about fMRI scanning that included preparing a child for the procedure. Images were acquired on a $1.5 \mathrm{~T}$ General Electric Signa HDx with an eight-channel headcoil employing parallel imaging with an acceleration factor of 2.0. Hearing was protected using earplugs and motion was minimized using soft pads fitted over the ears. Functional magnetic resonance images were acquired using the following parameters: TR $1800 \mathrm{~ms}$, TE $40 \mathrm{~ms}$, flip angle $90^{\circ}$ with whole brain coverage using 28 oblique axial slices, thickness $4 \mathrm{~mm}$ with $0.4 \mathrm{~mm}$ space between the slices; FOV $25.6 \times 25.6 \mathrm{~cm}$ with a $64 \times 64$ matrix. The first three images were excluded due to $\mathrm{T} 1$ equilibrium effects. For co-registration and volumetric analysis of functional data to Montreal Neurological Institute (MNI) standard space coordinates, T1-weighted 3D FSPGR sequence was performed using TR $12.4 \mathrm{~ms}$, TE $5.2 \mathrm{~ms}$ with $1 \mathrm{~mm}$ oblique axial slices, FOV $24.0 \mathrm{~cm} \times 24.0 \mathrm{~cm}$ with a $256 \times 256$ matrix; flip angle $20^{\circ} .290$ brain volumes were imaged in 8 min $42 \mathrm{~s}$.

\section{Assessing Working Memory Performance}

\section{N-Back Task}

We assessed WM performance using a visuospatial n-back task with two load levels (0- and 2-back tasks and a baseline visual fixation of background, Fig. 1) during fMRI to investigate memory load-related distribution of activation and deactivation in the brain (a detailed description of the WM paradigm is presented in Carlson et al. [14] and Vuontela et al. [94].

Before scanning, the memory tasks were explained and the subjects were allowed to practice the tasks with practice blocks to control that they had understood the nature of the tasks and performed them at an acceptable level $(\geq 15 / 20$ correct responses). The visual stimuli (duration $200 \mathrm{~ms}$, interstimulus interval (ISI) $2300 \mathrm{~ms}$ ) were light gray (60\% gray) squares $\left(2.2^{\circ} \times 2.2^{\circ}\right)$ presented randomly in one of eight locations around a fixation cross at eccentricities $4.2-6.0^{\circ}$. The presentation of the stimuli was controlled by a computer program (Presentation 10.10. Neurobehavioral Systems, Inc.).

The stimuli were projected onto a semitransparent screen and viewed by the subjects via a mirror mounted on the head coil. The video projector system was placed in the scanner room by incorporating a second Faraday cage inside the scanner Faraday cage.

An instruction figure (duration $2000 \mathrm{~ms}$ ) indicated the type of task to be performed at the beginning of each condition. In the 0-back task, the subject pressed the 


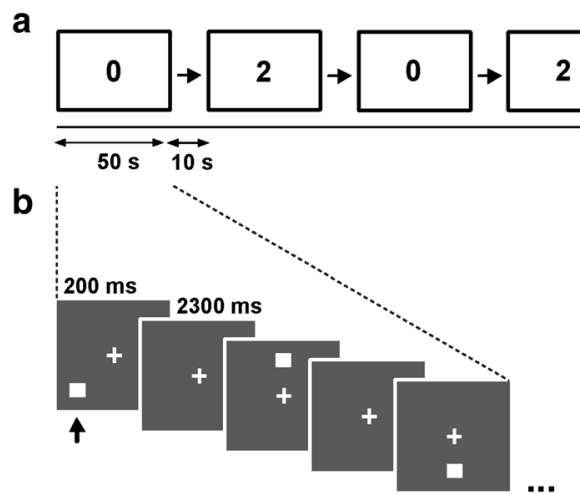

Fig. 1 The experimental design of the visuospatial n-back task a consisted of four blocks of 0-back and 2-back tasks presented in a semi-counterbalanced order. The duration of each block was $50 \mathrm{~s}$ and there was a 10-s baseline between the blocks (visual fixation of background indicated by arrows between the blocks). b The response

response button in the right hand if the stimulus appeared in a predetermined location (lower left location) and in the 2-back task when the current stimulus was in the same location as two trials before. In all other cases the subject pressed the response button in the left hand.

The subjects were allowed to blink normally but were instructed to maintain visual fixation throughout task performance. Both 0-back and 2-back tasks consisted of four blocks of 20 trials presented in a semi-random order producing 80 trials of 0-back and 2-back tasks, resulting in a total of 160 trials. There was a 10-s interval between each 0-back and 2-back task block that was used as a baseline. During the inter-block baseline the subjects were instructed to fixate on a small cross in the center of the display.

\section{Behavioral Data Analysis}

Behavioral data consisted of incorrect responses and response times (RTs) reflecting WM performance, and multiple and missed responses reflecting inhibitory and attentional mechanisms, respectively $[4,5]$. A multiple response was recorded when the subject pressed a button more than once per stimulus within a trial and a missed response when the subject failed to respond to the stimulus within a trial. Behavioral data analysis (percentages of incorrect, missed and multiple responses, RTs) was performed by using a three-way analysis of variance (ANOVA) for repeated measures. Group (ASDs, TD) and gender were the between subjects factors and load (0-back, 2-back) was the within-subjects factor in these analyses. The significance level was set at $P<0.05$. If the ANOVA gave a significant main effect, planned contrasts (within groups: paired two-tailed $t$ tests; between groups: unpaired two-tailed $t$ tests) were performed and the $P$ values were

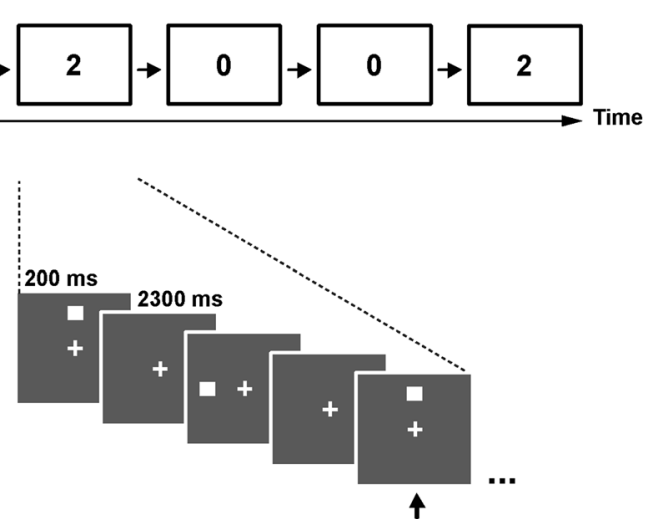

button in the right hand was pressed whenever the stimulus was in the predetermined location (0-back) or when the current square was in the same location as the square two trials before (2-back). In all other trials the response button in the left hand was pressed. Arrows here indicate the match locations

Bonferroni corrected to control for multiple comparisons. The Greenhouse-Geisser and Huynh-Feldt corrections were applied when necessary.

\section{fMRI Data Analysis}

FSL (FMRIB's Software Library, Oxford, UK) software versions 4.1.4 were used for pre-processing and analysis of the structural and functional data. Brain extraction for structural data was carried out using the brain extraction tool (BET) [85]. The functional data were motion corrected for translational and rotational movement using MCFLIRT $[39,40]$ and non-brain removal was performed using BET. Functional data were spatially smoothed with a $5.0 \mathrm{~mm}$ FWHM Gaussian kernel and subjected to high-pass temporal filtering (Gaussian-weighted least-squares straight line fitting, with sigma $=90.0 \mathrm{~s}$ ). The entire $4 \mathrm{D}$ dataset was grand-mean intensity normalized by a single multiplicative factor. Six motion parameters (x, y z translation and rotation) were used as temporal regressors in the FEAT analysis to compensate for sub-voxel motion artifacts. None of the included subjects had adjusted rotational or translational head movement more than 1 voxel width during scanning.

Individual time-series general linear modeling was carried out using FILM with local autocorrelation correction [100] and Z (Gaussianized T/F) statistic images were thresholded at $P=0.05$ (uncorrected). Registration to high-resolution structural and standard space images (MNI av) g152T1 template included in FSL) was carried out using FMRIB's Linear Image Registration Tool (FLIRT) [39, 40].

Higher-level analysis between the groups was carried out using FLAME (FMRIB's Local Analysis of Mixed 
Effects) stage 1 only (i.e., without the final MCMC-based stage) $[8,100]$, and $Z$ (Gaussianized T/F) statistic images were threshold-adjusted using a voxel-level $\mathrm{Z}$-score $>2.3$ and a cluster significance threshold of $P<0.05$ corrected for multiple comparisons (technical reports TR01CB1: General Multi-Level Linear Modelling for Group Analysis in FMRI [7], TR03MW1: Multi-Level Linear Modelling for FMRI Group Analysis Using Bayesian Inference [100]). Motion exclusion criteria were $1 \mathrm{~mm}$ translational or 1 rotation in any of the planes.

To determine the anatomical regions included in the voxel clusters, we used a custom made program that automated anatomical labeling by using the labeling of the ICBM individual brain by Tzourio-Mazoyer et al. [91]. FSL4 (Harvard-Oxford, Juelich, MNI) and AFNI [88] atlases were used in anatomical localization of significantly activated cortical areas.

\section{Results}

\section{Behavioral Performance}

Table 1 shows the main effects and interactions of the three-way ANOVA on the behavioral measures of the WM tasks. In both groups, the RTs, percentage of errors and multiple responses increased according to memory load (main effects of load: RTs $\mathrm{F}(1,46)=73.38, P<0.0001$, partial $\eta^{2}=0.61$; errors $\mathrm{F}(1,46)=13.12, P=0.0007$, partial $\eta^{2}=0.22$; and multiple responses $\mathrm{F}(1,46)=8.23$, $P=0.006$, partial $\eta^{2}=0.15$ ). There were no main effects of group (RTs $\mathrm{F}(1,46)=0.12, \quad P=0.74, \quad$ partial $\eta^{2}=0.002$; errors $\mathrm{F}(1,46)=2.25, \quad P=0.14$, partial $\eta^{2}=0.05$; missed responses $\mathrm{F}(1,46)=3.36, P=0.073$, partial $\eta^{2}=0.07$; multiple responses $\mathrm{F}(1,46)=3.62$, $P=0.063$, partial $\eta^{2}=0.07$ ), but in multiple responses there was a significant group $\times$ load interaction $\left(\mathrm{F}(1,46)=6.91, P=0.012\right.$, partial $\eta^{2}=0.13$ ) (Fig. 2ad). Planned contrasts (two-tailed $t$ tests) showed that the ASD group made more multiple responses than control adolescents in the 2-back $(\mathrm{t}(46)=2.52, P=0.04$, Bonferroni corrected, Cohen's $d=0.74$ ) but not in the 0-back $(\mathrm{t}(46)=0.19, P=0.85$, Cohen's $\mathrm{d}=0.06)$ tasks. The other interactions for multiple responses (group $\times$ gender, load $\times$ gender and load $\times$ group $\times$ gender) were not significant. No significant interactions were found for errors or missed responses. Average RTs were shorter in boys than girls (main effect of gender: $\mathrm{F}(1,46)=5.10, P=0.029$, partial $\eta^{2}=0.10$ ) (Fig. 2e), but the load $\times$ gender interaction $\left(\mathrm{F}(1,46)=3.07, P=0.09\right.$, partial $\left.\eta^{2}=0.06\right)$ and load $\times$ group $\times$ gender interaction $(\mathrm{F}(1,46)=3.00$, $P=0.09$, partial $\left.\eta^{2}=0.06\right)$ were not significant. Boys and girls did not differ in the percentage of errors, missed or multiple responses. There were no significant differences in the behavioral parameters between the children diagnosed with HFA or AS of the ASD group.

\section{Functional MRI Results}

In general the activation during 0-back task (i.e., 0-back $>$ baseline fixation) was found in bilateral insula, right cerebellum, left thalamus, and in large bilateral clusters between planum temporal and supramarginal gyrus left dominantly. Bilateral activation was also detected in the midline premotor areas in TD controls. The classical memory load related activation (2-back $>0$-back task) patterns were similar in both groups spatially and in intensity in bi-frontal and bi-parietal activations and in
Table 1 Main effects and interactions of group, gender and load on the behavioral measures of the performance of the WM tasks obtained in the three-way ANOVA

\begin{tabular}{llcll}
\hline Behavioral measure & Main effect/interaction & F & $P$ & Partial $\eta^{2}$ \\
\hline RTs (ms) & Group & 0.12 & n.s. & 0.002 \\
& Gender & 5.10 & 0.029 & 0.10 \\
Error (\%) & Load & 73.38 & $<0.0001$ & 0.61 \\
& Group & 2.25 & n.s. & 0.05 \\
& Gender & 0.77 & n.s. & 0.02 \\
Missed (\%) & Load & 13.12 & 0.0007 & 0.22 \\
& Group & 3.36 & n.s. & 0.07 \\
& Gender & 1.02 & n.s. & 0.02 \\
Multiple (\%) & Load & 2.85 & n.s. & 0.06 \\
& Group & 3.62 & n.s. & 0.07 \\
& Gender & 1.12 & n.s. & 0.02 \\
& Load & 8.23 & 0.006 & 0.15 \\
& Group $\times$ load & 6.91 & 0.012 & 0.13 \\
\hline
\end{tabular}

$R T s$ response times, $m s$ milliseconds, \% percentage, n.s. non-significant 

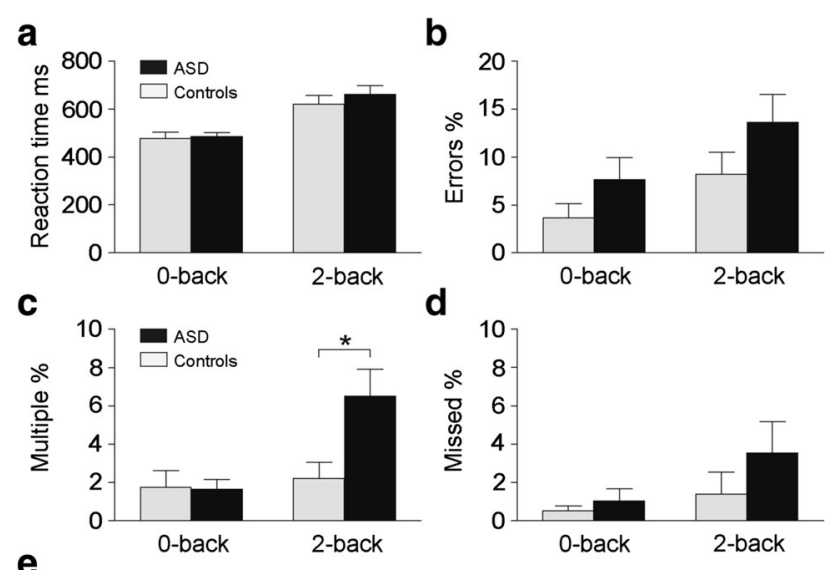

e

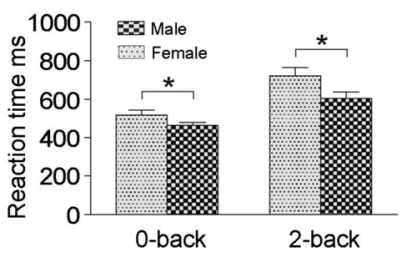

Fig. 2 a Response speed, b percentage of errors and $\mathbf{d}$ missed responses were not significantly different between ASD and TD groups, but $\mathbf{c}$ adolescents with ASDs made more multiple responses in the 2-back task (a significant load $\times$ group interaction). e In the performance of the tasks, boys responded faster than girls (a significant main effect of group). ${ }^{*} P<0.05$. Error bars indicate standard error of the mean

juxta-positional lobule. Deactivation patterns were detected in both groups in areas of the DMN with increasing spread and strength of deactivation within the DMN as a function of task load. Group differences in task responses are discussed below.

\section{Attentional Processing (0-Back vs. Baseline)}

Differences between the TD versus ASD groups in the 0-back versus baseline contrasts were located in the right superior (STG), middle (MTG) and inferior (ITG) temporal gyruses, right fusiform gyrus (FG) and in the cerebellum (Table 2; Fig. 3). The differences between the groups in the cortical areas were due to a stronger deactivation of these areas in the ASD sample compared to the TD sample during the performance of the 0-back task (i.e., ASDs $>$ TD subjects in the baseline $>0$-back contrast, Table 2). In the cerebellum, a continuous cluster of differentially activated voxels extended in right side from lobule VI towards vermis IX. This group difference was due to stronger activation in the TD sample compared to subjects with ASDs in the 0-back > baseline contrast in the upper vermian and lateral cerebellar area VI. Another group difference in the cerebellum comprising the cerebellum areas I, IV, V, VI, VIII, and IX, was mainly due to deactivation in the 0 -back task (i.e., baseline $>0$-back) that was stronger and more widespread in the ASDs group compared to TD controls (Fig. 3). These differences between the groups were localized in the right hemisphere (Fig. 3). Deactivation in the DMN areas did not differ between the ASD and TD groups.

\section{Memory Processing (2-Back vs. Baseline and 2-Back vS. 0-Back)}

In the 2-back versus baseline fixation contrasts, there were no statistically significant differences between the groups (Fig. 4). The differences in memory load effects (2-back vs. 0-back) between the groups were found in the right STG, supramarginal (SMG), postcentral (PostCG, primary somatosensory) and precentral (PreCG) gyruses, Rolandic operculum (RoOp), primary auditory cortices and in insula (Table 3; Fig. 5). The memory load-related differences between the groups originate from more activity in the TD than ASD group in the 0-back $>2$-back contrast. In other words, TD controls deactivated these areas more than the ASD group during the 2-back task compared with the 0-back task. In a subarea of the SMG, the memory loadrelated difference between the groups was due to stronger activation in the 2-back $>0$-back contrast in the ASD than TD group.

There were no significant differences between the groups in the DMN areas and in the frontal cognitive processing areas. The memory load-related signal changes in the cerebellum were also similar without any group differences.

\section{Modulation Capacity}

When combining all the three contrasts in the ROI based analysis, we were able to pinpoint interesting modulation in the control groups' brain activity. Insular areas showed a change in BOLD signal polarity from activation (0-back) into deactivation (2-back). This change was nearly absent in the ASD group who had non-significant activation during 0-back task. Figure 6 below illustrates mean activation and deactivation results with respect to task load.

\section{Discussion}

The present study examined attention and memory loaddependent differences in the brain activation and deactivation patterns between adolescents with ASD and ageand gender-matched TD controls. Behaviorally the subjects performed nearly identically and neural networks supporting WM were activated and DMN regions were deactivated in a comparable manner in adolescents with ASD and TD controls. However, marked differences between the 
Table 2 Brain regions showing TD controls $>$ ASD group differences in 0 -back $>$ baseline contrast $(\mathrm{Z}$ threshold $=2.3$, corrected $P<0.05)$

\begin{tabular}{llclccc}
\hline Hem & Area(s) & Vol & Max Z & X (mm) & Y (mm) & Z (mm) \\
\hline R & STG & 201 & 4.47 & 50 & -32 & 4 \\
R & CRL lobule IX & 193 & 3.19 & 4 & -54 & -40 \\
R & CRL lobule VI & 123 & 2.91 & 34 & -62 & -24 \\
L/R & Vermis IX & 98 & 3.14 & 6 & -60 & -40 \\
L & CRL lobule IX & 70 & 3.23 & -6 & -56 & -58 \\
L & CRL lobule VIII & 47 & 3.11 & -8 & -62 & -50 \\
R & CRL lobule VIII & 46 & 3.18 & 18 & -56 & -40 \\
R & FG & 30 & 2.74 & 40 & -50 & -22 \\
IR & CRL crus I & 26 & 3.15 & 34 & -60 & -34 \\
$\mathrm{R}$ & ITG & 26 & 2.8 & 58 & -20 & -18 \\
L/R & Vermis VIII & 22 & 2.86 & -2 & 68 & -34 \\
$\mathrm{R}$ & CRL lobules IV, V & 14 & 2.85 & 30 & -42 & -24 \\
\hline
\end{tabular}

The MNI coordinates and Z-values for the local maxima of the centers of mass of the voxel cluster and the number of voxels in the clusters

Hem hemisphere, $C R L$ cerebellum, $F G$ fusiform gyrus, $S T G$ superior temporal gyrus, $M T G$ middle temporal gyrus, $I T G$ inferior temporal gyrus, Vol number of voxels groups were found during the 0-back condition, which is an attentional task that only requires the detection of a predetermined stimulus but no manipulation or memorizing of earlier presented stimuli. In line with our previous results $[74,75]$, the current study suggests that while the degree of deactivation is normal within the DMN in adolescents with ASDs compared to TD controls, the deactivation in the ASD group spreads wider in several right temporal cortical areas and in the cerebellum during the attentional 0-back task performance. Furthermore, when the memory load is increased, the subjects with ASD fail to modulate activity in the sensory motor and auditory cortical areas and the insular cortex to the same extent as the control subjects.

\section{Attentional Processing}

Attentional deficits are a common and even shared behavioural/cognitive phenotype in ASD [17, 60, 62, 63]. The current study adds further proof on these findings showing increased rain activity during attention processing in visuospatial 0-back task. Harrison et al. [35] have recently shown that the strength and spatial extent of default mode deactivation reflects the cognitive load of the task at hand. We also found an increased spread of deactivation in the ASD group during the 0-back task versus baseline contrast outside of DMN. Several areas of the right temporal cortex including the ITG, MTG, STG, and regions of the FG and cerebellum area VI showed excess deactivation.

Our results suggest that the increased spread of deactivation to the right MTG and cerebellum during attentional 0-back task in adolescents with ASD might reflect controlling inhibitory activity to the relatively low task load. We did not detect statistically significant group differences in the performance of the 0-back task suggesting that the attentional task group differences in the brain activation and deactivation reflect successful compensatory actions against sub-optimal neuronal activity.

Mattila et al. [60, 63] and Christakou et al. [17] have shown that attentional deficits are a common and even shared neuropathological feature in ASD. The ASD subjects were shown to have more variable evoked responses [29]. The more variable evoked potential responses may be compensated by inhibiting excess neuronal activity by deactivation $[17,29]$. The current study adds further proof on these findings showing altered attention processing in visuospatial 0-back task. Liss et al. [56] suggested that over-focused attentional processing in ASD may be the result of hyperarousal, which might be detectable as disinhibition of competing sensory information that normally leads to attentional shifts. Keehn et al. hypothesized that atypical behavioral arousal regulation in persons with ASD results from early deficits in disengaging attention [45, 69]. Theoretically, the co-occurence of sensory modulation difficulties, arousal regulation problems, and atypical attention in people with ASD might be linked to dis-inhibition of sensory and attentional functions that becomes detectable as increased spread of BOLD deactivation [26, $28,29,69]$.

The deactivation increases in multiple regions during the attentional task in this study suggest increased inhibition of several functions including motor control (cerebellum, SM1), sensory processing (primary auditory cortex) and salience processing (insula). As there are no significant 


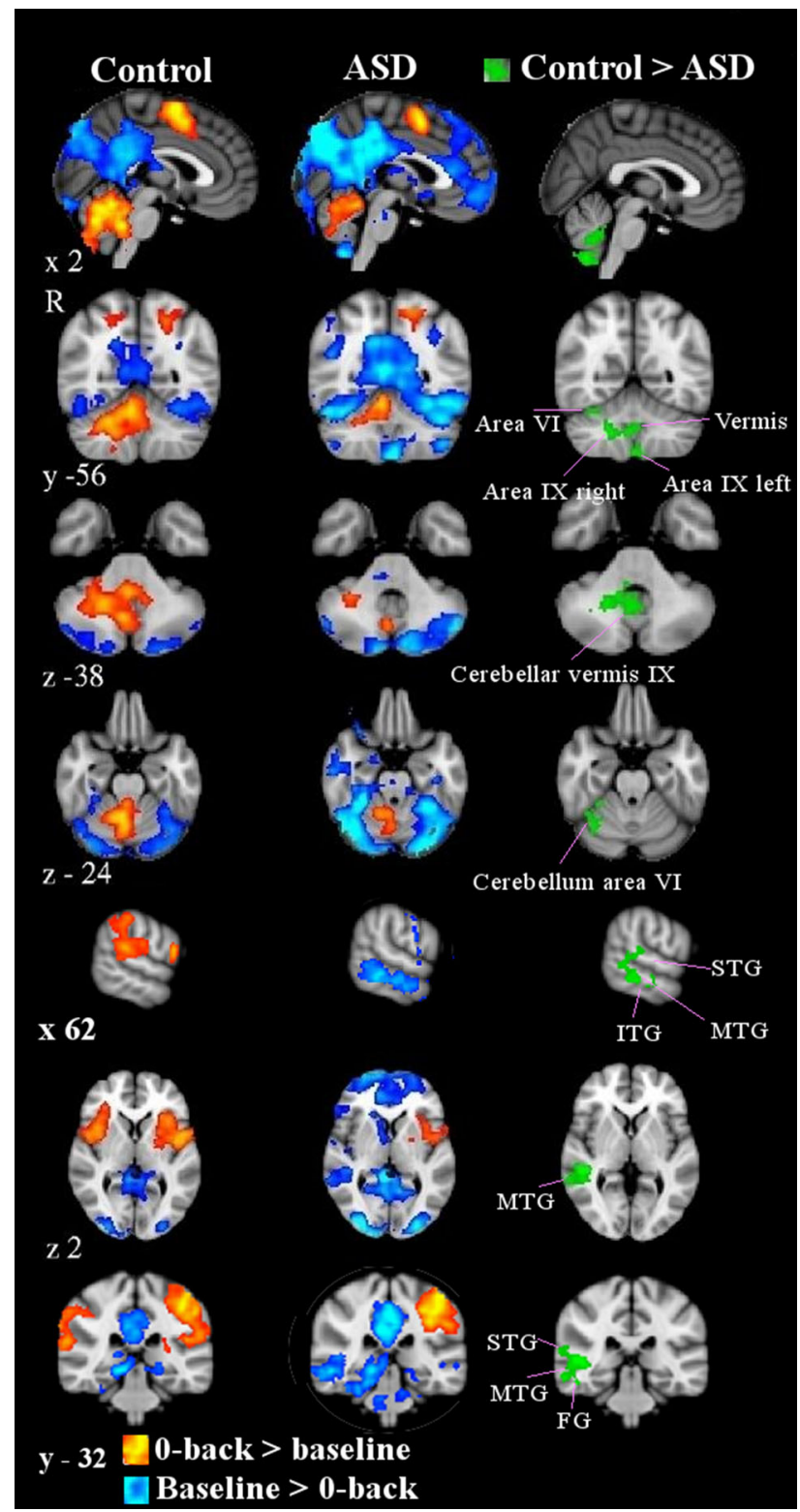

Fig. 3 Group activation (0-back $>$ baseline, warm colors) and deactivation (baseline $>0$-back, cold colors) maps for ASD $(n=28)$ and TD controls $(n=22)$. Differences between the TD versus ASD samples in the 0-back versus baseline (warm colors) contrasts were observed in the right superior (STG), middle (MTG) and inferior (ITG) temporal gyruses, right fusiform gyrus (FG) and in the cerebellum. These differences between controls and ASDs (green colors) were localized in the right hemisphere. Z-score threshold in the left and middle columns is $2.3<\mathrm{Z}<5$. Right column shows between-group comparison results with voxel-level Z-score threshold 2.3, $P=0.05$ corrected for multiple comparison. The level of the slice plane is shown on the left (coordinates are in the $2 \mathrm{~mm} 152 \mathrm{MNI}$ space). Brain images are presented in neurological convention (right is on the left) (Color figure online)

behavioral differences, the inhibition may be a required compensation for maintaining appropriate performance given the shown abnormal variance of the neuronal activity in ASD.

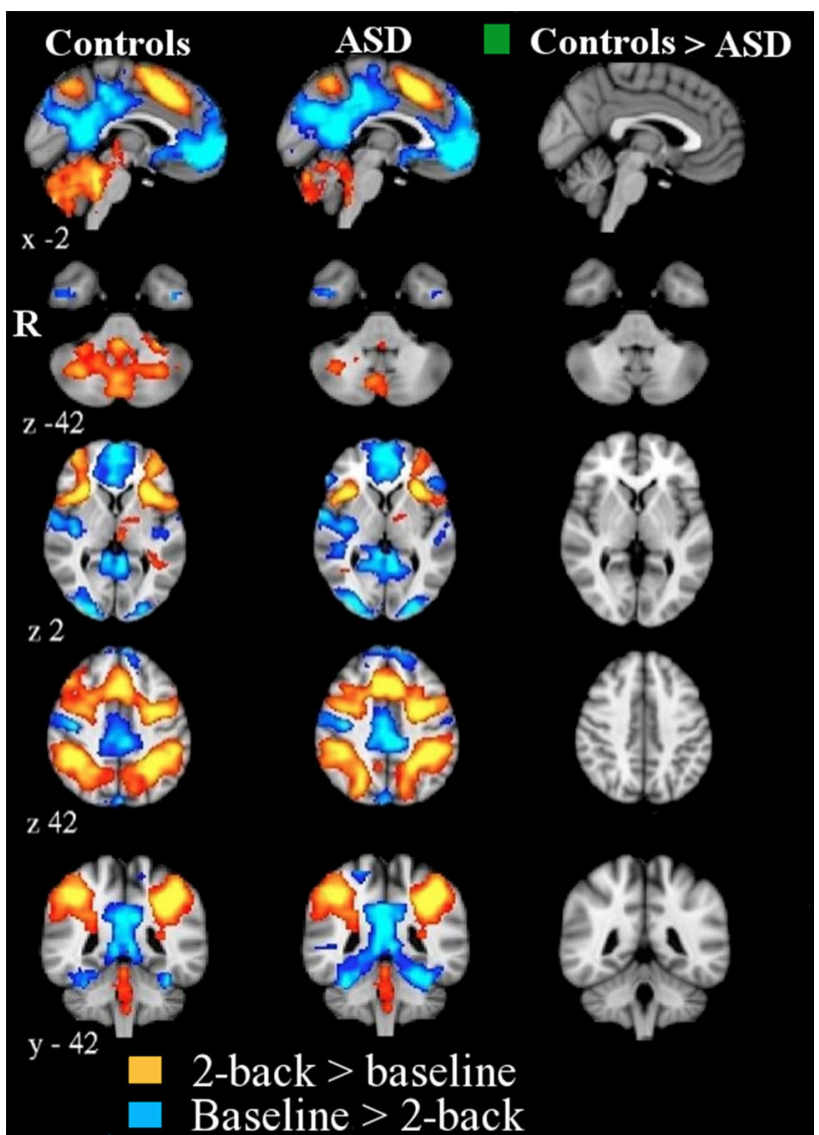

Fig. 4 Group activation (2-back $>$ baseline) and deactivation (baseline $>$ 2-back) maps for ASDs and TD controls. There were no statistically significant differences between the groups while 1st level analyses were threshold at $\mathrm{Z} \geq 2.3, P<0.05$ corrected. Z-score threshold in the left and middle columns is $2.3<\mathrm{Z}<5$. Brain images are presented in neurological convention (right is on the left)

Selective attention has been implicated as a limiting factor for the storage capacity of visual WM, since attention and WM share the same networks [20, 99]. Default mode deactivation has been commonly appreciated as a way to probe attentional level and in the present study, the ACC and other areas of the DMN were deactivated similarly in adolescents with ASDs and in TD controls. In contrast to our investigation, an earlier fMRI study using a word counting Stroop task reported a lack of deactivation in the medial PFC, rostral ACC, PCC and precuneus in the ASD group compared to TD controls in the number versus baseline condition [49]. In non-social studies, group comparisons have shown greater activation for subjects with ASDs in the rostal ACC region compared to healthy controls $[33,96]$.

Since attentional deficits can be augmented with psychopharmacological interventions it might be possible to use it in ASD. Moreover in the future it might be worthwhile to probe the attentional functions as a biomarker for 
Table 3 Brain regions showing TD control $>$ ASD group differences in 0-back $>2$-back contrast $(\mathrm{Z}$-threshold $=2.3$, corrected $P<0.05)$

\begin{tabular}{|c|c|c|c|c|c|c|}
\hline Hem & Area (s) & Vol & Max Z & $\mathrm{X}(\mathrm{mm})$ & $\mathrm{Y}(\mathrm{mm})$ & $\mathrm{Z}(\mathrm{mm})$ \\
\hline $\mathrm{R}$ & PostCG & 277 & 4.75 & 60 & -10 & 26 \\
\hline $\mathrm{R}$ & Insula & 264 & 3.47 & 48 & -4 & 2 \\
\hline $\mathrm{R}$ & STG & 168 & 3.45 & 62 & -22 & 16 \\
\hline $\mathrm{R}$ & RoOp & 121 & 3.39 & 50 & -2 & 2 \\
\hline $\mathrm{R}$ & SMG & 117 & 3.51 & 62 & -22 & 18 \\
\hline $\mathrm{R}$ & Primary auditory cortex & 83 & 3.19 & 52 & -16 & 8 \\
\hline $\mathrm{R}$ & PreCG & 71 & 4.06 & 60 & 0 & 26 \\
\hline
\end{tabular}

The MNI coordinates and Z-values for the local maxima of the centers of mass of the voxel cluster and the number of voxels in the clusters

Hem hempisphere, PreCG precentral gyrus, RoOp Rolandic operuculum, PostCG postcentral gyrus, SMG supramarginal gyrus, $S T G$ superior temporal gyrus, Vol number of voxels identifying subjects that may benefit from such treatments. Importantly it may be that the deactivation rather than the activation patterns and their anatomical spread outside default mode network could prove beneficial in such efforts.

\section{Working Memory}

In the current study, most of the WM related network and the DMN were similarly recruited in the 2-back task in ASD and controls when contrasted to the fixation baseline showing the classical memory load related fronto-parietal activation patterns in both groups [12-14, 68, 89, 94]. In other words, both groups activated their brain with similar magnitude at this 2-back stage as compared to fixation baseline task.

However, a contrast between attentional 0-back task versus 2-back task revealed widespread differences between the groups, extending those seen in the attention task 0-back versus baseline fixation condition. The differences extended to the primary auditory, somatosensory and motor areas, insula and SMG, interestingly again all in the right hemisphere. Compared to the 0-back task, the TD controls were able to increase their brain activation and deactivation during the 2-back task, while the ASD subjects lacked this ability to modulate activity levels. This matches with a recent meta-analysis that ASD is related to a lack of modulation of task demands [73].

Typical bottle neck areas of memory-load should be the prefrontal and parietal attention networks but our results showed differences in the right primary sensory, and motor and insular areas [55]. While switching from attentional 0-back to 2-back task increases activation and deactivation in controls, the same does not occur in the ASD group. Moreover, we detected more multiple responses in the ASD group than in the controls in the 2-back WM task during which the right insular cortex, in addition to the primary somatosensory and primary auditory cortex, showed deficient modulation of activation. This may be seen as a sign of dis-inhibition.

Insula is linked to failed error processing of repetitive responses in ASD [31, 43]. Further studies with more varied stimulus loads in an event related task/naturalistic moving video task might add more knowledge on the issue. It is also known that ASD subjects have sensory modulation deficits with both sensory under/overload as a characteristic feature in ASD [59]. Moreover, the primary auditory and somatosensory areas may also function as a short term memory storage and may thus directly explain some of the WM task load findings [55].

Recently the functional connectivity of the salience network (SN) was found to be a predictor of ASD symptomatology [93]. A key area of the $\mathrm{SN}$ is insula, which also performs mirror-neuron functionality and integrates interoceptive bodily information for predictive brain functions [83, 93]. A SN dysfunction, including the anterior insula, results in a difficulty in operating social cognition and selfreferential processing [90, 91]. Altered emotional valence scaling was detected in bilateral insula and primary sensory areas earlier [72-75], while WM abnormalities in these areas in ASD in the current study were detected only in the right insula. Activation of the right insula has been widely reported during error processing and, it has usually been associated with a negative emotional state [49]. Two studies have shown abnormal activity in right insula during error processing and inhibitory tasks in children with autism $[31,43]$.

\section{Cerebellum}

Other areas where one might expect to detect alteration in function during repetitive behavior deficit could be the inferior frontal cortex or cerebellum [54], but there was no sign of differential activity or deactivation in these areas [54]. A recent meta-analysis detected cerebellar abnormalities in simple motor tasks while more complex tasks 

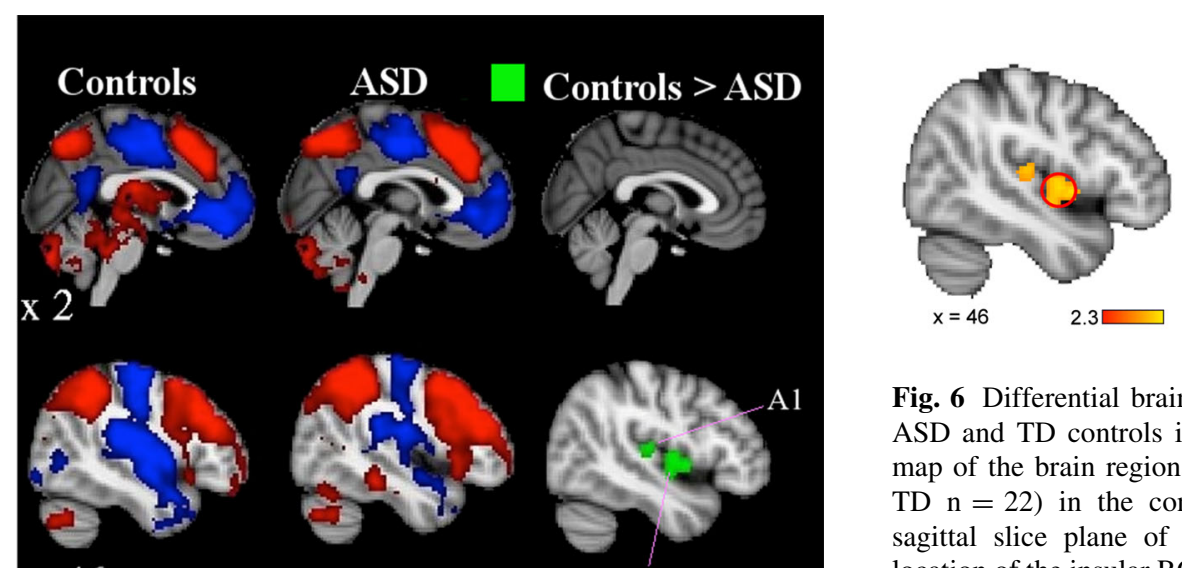

x 46 INS

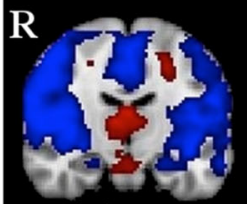

$\mathrm{y}-14$
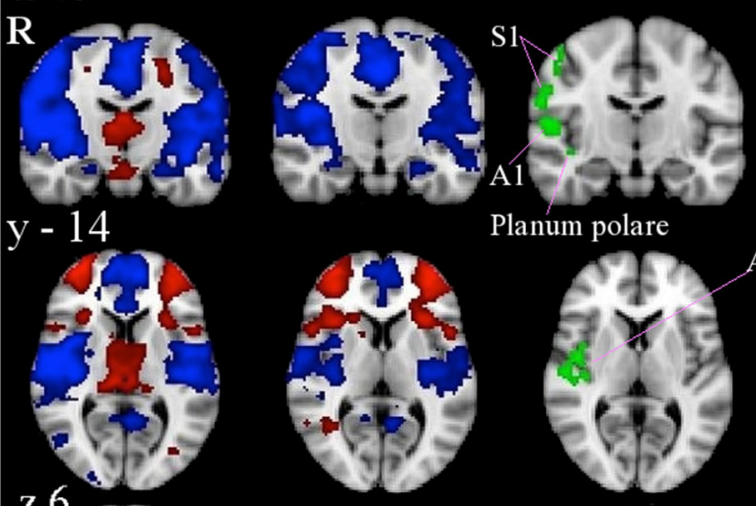

Planum polare

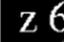

6
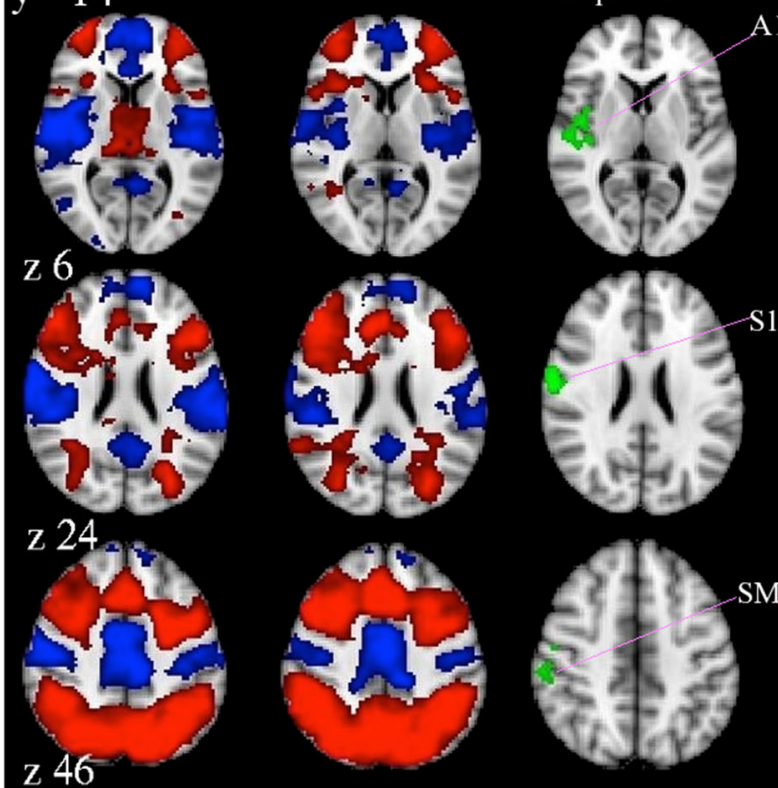

A1
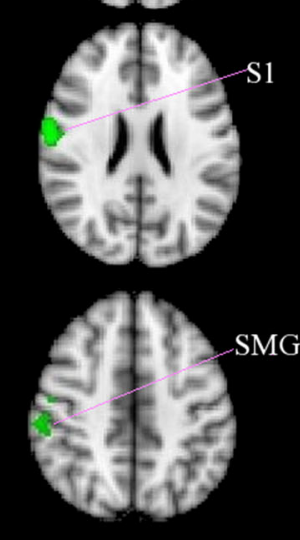

2-back $>0$-back

0 -back $>2$-back

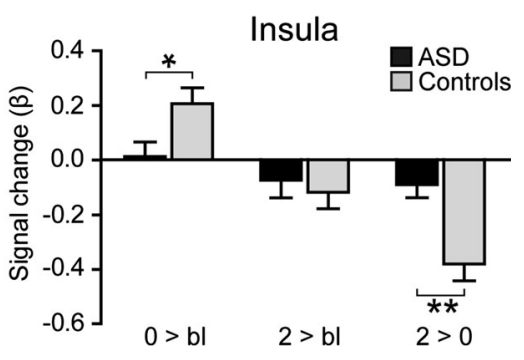

Fig. 6 Differential brain responses in the insula in adolescents with ASD and TD controls in the 0-back and 2-back tasks. A statistical map of the brain regions showing a group difference (ASD $\mathrm{n}=28$, TD $\mathrm{n}=22$ ) in the contrast 0 -back $>2$-back is displayed on the sagittal slice plane of the MNI standard brain. The approximate location of the insular ROI is indicated with a red circle. The columns illustrate the mean signal change in the insula in the 0-back $>$ baseline, 2-back $>$ baseline and 2-back $>0$-back contrasts. The TD controls show stronger modulation of brain activity than the ASD group. $O$ 0-back; 22 -back; $b l$ baseline. ${ }^{*} P<0.05$, ${ }^{*} P P<0.01$. Error bars indicate standard error of the mean (Color figure online)

lacked differences [73]. Our results corroborate these findings with respect to WM task load; the attentional 0 -back task presented mainly deactivation changes which were absent from the 2-back task load. At 2-back load, multiple responses occurred which might be related to reduced capacity of brain activity modulation with respect to task load. In the cerebellum, the lack of modulation of the brain activity in higher task load and excess de/activation in low task load suggest that the ASD brain fails to increase its activity level according to the task load. As the performance fails at higher task load, the same ceiling effects seems plausible than in the right cerebral hemisphere insula, sensory regions and auditory areas.

At 0-back the activation was stronger in controls, while the deactivation in the ASD group was increased. The activation increase was more dominant in the right side periventricular areas, while the deactivation was more prominent in the lateral parts of the cerebellum. This finding suggests that the increased deactivation may be a compensatory mechanism, since there were no behavioral differences between groups at 0-back task load. The lack of activation in ASD is challenging to explain with respect to behavioral changes. Christakou et al. [17] noticed increased activation of the cerebellum in ADHD compared to controls and suggested it to be a compensatory mechanism. Our results suggest that the 0-back attentional task requires deactivation as a compensatory mechanism.

\section{Right Hemisphere Dominance}

The differences in the brain activation patterns between the subjects with ASD and TD adolescents were detected 
predominantly in the right hemisphere. Interestingly, individuals with $\mathrm{AS}$, right frontal excisions or temporal brain lobectomy show more deficits in spatial WM than subjects with left-sided lesions/lobectomies [67]. A similar distinction between hemispheres was recently detected in a fMRI study of children showing pervasive rightward asymmetry in resting state networks and right insula [27].

Findings of our previous studies in the same subjects as in the current study using either diffusion tensor imaging (DTI) or fMRI during resting state or a facial expression task, all suggest a right-sided changes in the brains of adolescent with ASD [9, 72, 75]. Regional baseline homogeneity of BOLD spontaneous brain activity was also detected in the right insula [72], and fearful facial expressions were shown to increase deactivation in the right visual cortex (V2 BA18) [75]. Furthermore, white matter tracts connecting the visual and insular areas in the right inferior fronto-occipital fasciculus (iFOF) had reduced fractional anisotropy (FA) in the right periventricular area in adolescent with ASD [9].

Importantly, the IFOF connects DMN areas and SN structures. Our group has recently shown resting state disconnectivity between the extremes of the right IFOF; the DMN anterior and retrosplenial connectivity was reduced [86]. Taken together there seems to be a disconnection along the IFOF in ASD subjects. It may be that the disconnectivity within the DMN is related to the compensatory increase in spread of deactivation outside the DMN proper. Further investigations with multimodal magnetic resonance encephalography (MREG) could reveal the neurophysiological mechanisms behind these disconnection findings.

\section{Reduced Task-Load Modulation}

It has been suggested that subjects with ASD perceive and process information too intensively and their cognitive capacity saturates in increasing information levels without being able to modulate according to demand $[59,73]$. Our findings agree somewhat with the notion of dis-inhibition since we detected inability to deactivate the right insula, primary auditory and somatosensory cortices during memory load increase. More importantly the current results suggest a lack of modulation capacity of brain activity.

The disability to proportionate brain activity in the ASD group may be related to altered salience processing in the right insula, where also resting state homogeneity was found to be altered in our group [92]. The WM tasks of the present study and the facial expression tasks of our previous studies $[74,75]$ showed differences in the right insula between the ASD and TD groups. There, too, the modulation of brain activation and especially deactivation with valence was different compared to TD controls.

\section{Limitations}

There were some limitations in our study; (1) We did not measure the IQ of controls, instead we measured their school performance, which is not straight forward comparable with the IQ. However, we assume that this did not really affect the results, as the probands FSIQ was $>75$, and the controls school performance ranged between 7 and 9.75 (US D to A) and they were drawn from mainstream education, which in Finland are only for children with at least average intelligence. Additionally, the tasks in fMRI were relatively simple attention and WM tasks. (2) As the functional alterations in ASD depend on the age and development it might have been beneficial to use the age or development state of the subject as a co-variate. We did not perform age wise analysis since the groups were matched, which to a large extent reduces developmental aspects within the data. (3) As suggested by Schlaggar et al. [79], the differences in activation could have been related to task set maintenance, task difficulty, error-related activation, or to cognitive activity (or lack thereof) unrelated to task performance. In the future, these aspects of task performance could be studied in more detail with an event-related task paradigm with faster MREG sequences that increase statistical power several fold. (4) Address the impact of preceding task-effect on the consecutive in-between the blocks baseline fMRI values as the strength of task-related de/activation can affect the consecutive baseline fMRI findings, and may explain some of the deactivation issues related to our results. One way to address this issue would have been to examine the consecutive baseline values for consistency. However, we were unable to examine that in FSL or in any other GML tools. On the other hand, we believe that this is a universal phenomenon in the brain that applies to every functional area to some extent at least.

\section{Summary}

Typical visual WM-related areas were normally activated and DMN was deactivated in ASD as a function of task load. Attentional processing showed both reduced activation and increased deactivation in the cerebellum and in several right temporal cortical areas increased deactivation in the absence of behavioral performance changes. Increasing task load resulted in inadequate modulation of brain activity in right insula, primary somatosensory, motor and auditory cortices and the performance showed multiple responses. The neuroimaging changes during attentional task may be a sign of compensatory mechanisms enabling normal behavioral performance. The inadequate load dependent modulation during increased memory load suggest of lacking compensatory potential in ASD. 
Acknowledgments We thank the adolescents and their parents, who graciously gave their time to participate in this study. This study received financial support from the Alma and K. A. Snellman Foundation, Oulu, Finland; the Emil Aaltonen Foundation, Finland; Northern Ostrobothnia Hospital District; the Sigrid Jusélius Foundation, Finland; the Thule Institute, University of Oulu, Finland; the Lundbeck Foundation, Turku, Finland; the Rinnekoti Research Foundation, Espoo, Finland; the Child Psychiatric Research Foundation, Finland. This study was also funded by the Academy of Finland (Grants \#117111, \#123772, \#214412, \#259752, \#273147)], the aivoAALTO project, the Päivikki and Sakari Sohlberg Foundation and Finnish Medical Foundation grants. The Graduate School of Circumpolar Wellbeing, Health and Adaptation is acknowledged for its support. We would also like to thank the National Alliance for Autism Research for financial support granted to David Pauls. For data collection we wish to thank Child Psychiatrist, Ph.D. SirkkaLiisa Linna and Ph.D. Marko Kielinen.

\section{Compliance with Ethical Standards}

Conflict of interest The authors have no conflicting interests to report.

\section{References}

1. Alvarez JA, Emory E (2006) Executive function and the frontal lobes: a meta-analytic review. Neuropsychol Rev 16:17-42

2. American Psychiatric Association (2000) Diagnostic and statistical manual of mental disorders, 4th edn. American Psychiatric Association, Washington DC

3. American Psychiatric Association (2013) Diagnostic and statistical manual of mental disorders, 5th edn. American Psychiatric Association, Arlington

4. Aronen ET, Mäkelä J, Cacciatore R, Almqvist F (1998) KIDDIE-SADS-PL-Finnish translation. University of Helsinki, Department of Child Psychiatry, Hospital for Children and Adolescents, Helsinki

5. Aronen ET, Vuontela V, Steenari MR, Salmi J, Carlson S (2005) Working memory, psychiatric symptoms, and academic performance at school. Neurobiol Learn Mem 83:33-42

6. Awh E, Vogel E, Oh S-H (2006) Interactions between attention and working memory. Neuroscience 139:201-208

7. Beckmann CF, Smith S, Jenkinson M (2004) General multilevel linear modeling for group analysis in FMRI. NeuroImage 21:1732-1747

8. Behrmann M, Thomas C, Humphreys K (2006) Seeing it differently: visual processing in autism. Trends Cognit Sci 10:258-263

9. Bode MK, Mattila ML, Kiviniemi V, Rahko J, Moilanen I et al (2011) White matter in autism spectrum disorders-evidence of impaired fiber formation. Acta Radiol 52:1169-1174

10. Boucher J (2009) The autistic spectrum: characteristics, causes, and practical issues. SAGE Publications LTD, Los Angeles

11. Bowler DM (2007) Autism spectrum disorders: psychological theory and research. Wiley, Chichester

12. Braver TS, Cohen JD, Nystrom LE, Jonides J, Smith EE, Noll DC (1997) A parametric study of prefrontal cortex involvement in human working memory. NeuroImage 5:49-62

13. Braver TS, Barch DM, Gray JR, Molfese DL, Snyder A (2001) Anterior cingulate cortex and response conflict: effects of frequency, inhibition and errors. Cereb Cortex 11:825-836

14. Carlson S, Martinkauppi S, Räma P, Salli E, Korvenoja A et al (1998) Distribution of cortical activation during visuospatial n-back tasks as revealed by functional magnetic resonance imaging. Cereb Cortex 8:743-752
15. Carninale RC, Ship P, Fishman I, Ford LM, Müller RA (2013) Pervasive rightward asymmetry shifts of functional networks in autism spectrum disorder. JAMA Psychiatry 70:975-982

16. Caron MJ, Mottron L, Rainville C, Chouinard S (2004) Do high functioning persons with autism present superior spatial abilities? Neuropsychologia 42:467-481

17. Christakou A, Murphy CM, Chantiluke K, Cubillo AI, Smith AB, Giampietro V et al (2013) Disorder-specific functional abnormalities during sustained attention in youth with Attention Deficit Hyperactivity Disorder (ADHD) and with autism. Mol Psychiatry 18:236-244

18. Cohen JD, Perlstein WM, Braver TS, Nystrom LE, Noll DC et al (1997) Temporal dynamics of brain activation during a working memory task. Nature 386:604-608

19. Corbetta M, Shulman GL (2002) Control of goal-directed and stimulus-driven attention in the brain. Nat Rev Neurosci 3:201-215

20. Cowan $N$ (2001) The magical number 4 in short-term memory: a reconsideration of mental storage capacity. Behav Brain Sci 24:114-185

21. Dapretto M, Davies MS, Pfeifer JH, Scott AA, Sigman M et al (2006) Understanding emotions in others: mirror neuron dysfunction in children with autism spectrum disorders. Nat Neurosci 9:28-30

22. Dawson G, Webb S, Schellenberg GD, Dager S, Friedman S et al (2002) Defining the broader phonotype of autism: genetic, brain, and behavioral perspectives. Dev Psychopathol 14:581-611

23. Dawson G, Carver L, Meltzoff AN, Panagiotides H, McPartland $J$ et al (2002) Neural correlates of face and object recognition in young children with autism spectrum disorder, developmental delay, and typical development. Child Dev 73:700-717

24. De Baene W, Albers AM, Brass M (2012) The what and how components of cognitive control. Neuroimage 63:203-211

25. Dichter GS (2012) Functional magnetic resonance imaging of autism spectrum disorders. Dialogues Clin Neurosci 14:319-351

26. Dickstein DP, Pescosolido MF, Reidy BL, Galcan T, Kim KL et al (2013) Developmental meta-analysis of the functional neural correlates of autism spectrum disorders. J Am Acad Child Adolec Psychiatry 52:279-289

27. Di Martino A, Ross K, Uddin LQ, Sklar AB, Castellanos FX et al (2009) Functional brain correlates of social and nonsocial processes in autism spectrum disorders: an activation likelihood estimation meta-analysis. Biol Psychiatry 65:63-74

28. Dinstein I, Thomas C, Behrmann M, Heeger DJ (2008) A mirror up to nature. Curr Biol 18:13-18

29. Dinstein I, Heeger DJ, Lorenzi L, Minschew NJ, Malach R et al (2012) Unreliable evoked responses in autism. Neuron 75:981-991

30. Ehlers S, Gillberg C, Wing L (1999) A screening questionnaire for Asperger syndrome and other high-functioning autism spectrum disorders in school age children. J Autism Dev Disord 29:129-141

31. Goldberg MC, Spinelli S, Joel S, Pekar JJ, Denckla MB et al (2011) Children with high functioning autism show increased prefrontal and temporal cortex activity during error monitoring. Dev Cogn Neurosci 1:47-56

32. Gusnard DA, Raichle ME (2001) Searching for a baseline: functional imaging and the resting human brain. Nat Rev Neurosci 2:685-694

33. Happé F, Ehlers S, Fletcher P, Frith U, Johansson M et al (1996) Theory of mind in the brain. Evidence from a PET scan study of Asperger syndrome. NeuroReport 8:197-201

34. Happé F, Frith U (2006) The weak coherence account: detailfocused cognitive style in autism spectrum disorders. J Autism Dev Disord 36:5-25

35. Harrison BJ, Pujol J, Contreras-Rodriguez O, Soriano-Mas C, Lopez-Sola M et al (2011) Task induced deactivation from rest extends beyond the default mode brain network. PLoS ONE 6(7):1-9 
36. Hauck M, Fein D, Maltby N, Waterhouse L, Feinstein C (1998) Memory for faces in children with autism. Child Neuropsychol 4:187-198

37. Haxby JV, Hoffman EA, Gobbini MI (2002) Human neural systems for face recognition and social communication. Biol Psychiatry 51:59-67

38. Jansson-Verkasalo E, Kujala T, Jussila K, Mattila ML, Moilanen I, Näätänen R et al (2005) Similarities in the phenotype of the auditory neural substrate in children with Asperger syndrome and their parents. Eur J Neurosci 22:986-990

39. Jenkinson M, Smith S (2001) A global optimisation method for robust affine registration of brain images. Med Image Anal 5:143-156

40. Jenkinson M, Bannister P, Brady M, Smith S (2002) Improved optimization for the robust and accurate linear registration and motion correction of brain images. Neuroimage 17:825-841

41. Just MA, Keller TA, Malave VL, Kana RK, Varma S (2012) Autism as a neural systems disorder: a theory of frontal-posterior underconnectivity. Neurosci Biobehav Rev 36:1292-1313

42. Kadesjö B, Gillberg C, Hagberg B (1999) Brief report: autism and Asperger syndrome in seven-year-old children: a total population study. J Autism Dev Disord 29:327-331

43. Kana RK, Keller TA, Minshew NJ, Just MA (2007) Inhibitory control in high-functioning autism: decreased activation and underconnectivity in inhibition networks. Biol Psychiatry 62:198-206

44. Kaufman J, Birmaher B, Brent D, Rao U, Flynn C, Moreci P, Williamson D, Ryan N (1997) Schedule for affective disorders and schizophrenia for school-age children-present and lifetime version (K-SADS-PL): initial reliability and validity data. J Am Acad of Child Adolesc Psychiatry 36:980-988

45. Keehn B, Muller RA, Townsend J (2013) Atypical attentional networks and the emergence of autism. Neurosci Biobehav Res 37:164-183

46. Kennedy DP, Redcay E, Courchesne E (2006) Failing to deactivate: resting functional abnormalities in autism. Proc Natl Acad Sci USA 103:8275-8280

47. Kennedy DP, Courchesne E (2008) The intrinsic functional organization of the brain is altered in autism. Neuroimage 39:1877-1885

48. Kenworthy L, Yerys BE, Anthony LG, Wallace GL (2008) Understanding executive control in autism spectrum disorders in the lab and in the real world. Neuropsychol Rev 18:320-338

49. Klein TA, Ullsperger M, Danielmeier C (2013) Error awareness and the insula: links to neurological and diseases. Front Hum Neurosci 7:1-13

50. Koshino H, Kana RK, Keller TA, Cherkassky VL, Minshew NJ et al (2008) fMRI investigation of working memory for faces in autism: visual coding and underconnectivity with frontal areas. Cereb Cortex 18:289-300

51. Kuusikko S, Pollock-Wurman R, Jussila K, Carter AS, Mattila ML et al (2008) Social anxiety in high-functioning children and adolescents with autism and asperger syndrome. J Autism Dev Disord 38:1697-1709

52. Kuusikko-Gauffin S, Jansson-Verkasalo E, Carter A, PollockWurman R, Jussila K et al (2011) Face memory and object recognition in children with high-functioning autism or Asperger syndrome and in their parents. Res Autism Spec Disorders 5:622-628

53. LaBar KS, Gitelman DR, Parrish TB, Mesulam M (1999) Neuroanatomic overlap of working memory and spatial attention networks: a functional MRI comparison within subjects. Neuroimage 10:695-704

54. Lee PS, Yerys BE, Della Rosa A, Foss-Feig J, Barnes KA et al (2007) Functional connectivity of the inferior frontal cortex changes with age in children with autism spectrum disorders: a fcMRI study of response inhibition. Cereb Cortex 19:1787-1794
55. Linden DE (2007) The working memory networks of the human brain. Neuroscientist 13:257-267

56. Liss M, Saulnier C, Kinsbourne DF, Kinsbourne M (2006) Sensory and attention abnormalities in autistic spectrum disorders. Autism 10:155-172

57. Lord C, Rutter M, LeCouteur A (1995) Autism diagnostic interview-revised, 3rd edn. Western Psychological Services, Los Angeles

58. Lord C, Rutter M, DiLavore PC, Risi S (2000) Autism diagnostic observation schedule. Western Psychological Services, Los Angeles

59. Markram K, Markram H (2010) The intense world theory-a unifying theory of the neurobiology of autism. Front Hum Neurosci 4:1-29

60. Mattila ML, Kielinen M, Jussila K, Linna SL, Bloigu R et al (2007) An epidemiological and diagnostic study of Asperger syndrome according to four sets of diagnostic criteria. J Am Acad Child Adolesc Psychiatry 46:636-646

61. Mattila ML, Jussila K, Kuusikko S, Kielinen M, Linna SL, Ebeling $\mathrm{H}$ et al (2009) When does the autism spectrum screening questionnaire (ASSQ) predict autism spectrum disorders in primary school-aged children? Eur Child Adolesc Psychiatry 18:499-509

62. Mattila M-L, Hurtig T, Haapsamo H, Jussila K, Kuusikko S et al (2010) Psychiatric comorbid disorders associated with Asperger syndrome and high-functioning autism: prevalence and impairment in a combined total population and outpatient study. J Autism Dev Disor 40:1080-1093

63. Mattila ML, Kielinen M, Linna SL, Jussila K, Ebeling H, Bloigu $\mathrm{R}$ et al (2011) Autism spectrum disorders according to DSM-IVTR and comparison with DSM-5 draft criteria: an epidemiological study. J Am Acad Child Adolesc Psychiatry 50:583-592

64. Mattila ML, Jussila K, Linna SL, Kielinen M, Joseph RM et al (2012) Validation of the Finnish autism spectrum screening questionnaire (ASSQ) for clinical settings and total population screening. J Autism Dev Disord 42:2162-2180

65. Miller BT, D́Esposito M (2005) Searching for "the top" in topdown control. Neuron 48:535-538

66. Minshew NJ, Luna B, Sweeney JA (1999) Oculomotor evidence for neocortical systems but not cerebellar dysfunction in autism. Neurology 52:917-922

67. Morris RG, Rowe A, Fox N, Feigenbaum JD, Miotto EC et al (1999) Spatial working memory in Asperger's syndrome and in patients with focal frontal and temporal lobe lesions. Brain Cogn 41:9-26

68. Nelson C, Bloom F, Cameron J, Amaral D, Dahl R et al (2002) An integrative, multidisciplinary approach to the study of brainbehavior relations in the context of typical and atypical development. Dev Psychopathol 14:499-520

69. Orekhova EV, Stroganova TA (2014) Arousal and attention reorienting in autism spectrum disorders: evidence from auditory event-related potentials. Front Hum Neurosci 8:34

70. Ozonoff S, Pennington BF, Rogers SJ (1991) Executive function deficits in high-functioning autistic individuals: relationship to theory of mind. J Child Psychol Psychiatry 32:1081-1105

71. Owen AM, McMillan KM, Laird AR, Bullmore E (2005) N-back working memory paradigm: a meta-analysis of normative functional neuroimaging studies. Hum Brain Mapp 25:46-59

72. Paakki JJ, Rahko J, Long X, Moilanen I, Tervonen $\mathrm{O}$ et al (2010) Alterations in regional homogeneity of resting-state brain activity in autism spectrum disorders. Brain Res 1321:169-179

73. Philips RC, Dauvermann MR, Whalley HC, Baynham K, Lawrie SM (2012) A systematic review and meta-analysis of the fMRI investigation of autism spectrum disorders. Neurosci Biobehav Rev 36:901-942 
74. Rahko J, Paakki JJ, Starck T, Nikkinen J, Remes J et al (2010) Functional mapping of dynamic happy and fearful facial expression processing in adolescents. Brain Imaging Behav 4:164-176

75. Rahko JS, Paakki JJ, Starck TH, Nikkinen J, Pauls DL, Kätsyri JV et al (2012) Valence scaling of dynamic facial expressions is altered in high-functioning subjects with autism spectrum disorders: an fMRI study. J Autism Dev Disord 42:1011-1024

76. Rumsey JM (1985) Conceptual problem-solving in highly verbal, nonretarded autistic men. J Autism Dev Disord 5:23-36

77. Rumsey JM, Hamburger SD (1990) Neuropsychological divergence of high-level autism and severe dyslexia. J Autism Dev Disord 20:155-168

78. Russell J (1997) Autism as an executive disorder. Oxford University Press, Oxford

79. Schlaggar BL, Brown TT, Lugar HM, Visscher KM, Miezin FM et al (2002) Functional neuroanatomical differences between adults and school-age children in the processing of single words 296:1476-1479

80. Schultz RT, Grelotti DJ, Klin A, Kleinman J, Van der Gaag C et al (2003) The role of the fusiform face area in social cognition: implications for the pathobiology of autism. Philos Trans R Soc Lond B Biol Sci 358:415-427

81. Seniów J (2012) Executive dysfunctions and frontal syndromes. Front Neurol Neurosci 30:50-53

82. Shulman RG, Rothman DL, Hyder FA (2007) BOLD search for baseline. Neuroimage 36:277-281

83. Singer T, Critchley HD, Preuschoff K (2009) A common role of insula in feelings, empathy and uncertainty. Trends Cogn Sci 13:334-340

84. Smalley SL, McGough JJ, Moilanen IK, Loo SK, Taanila A et al (2007) Prevalence and psychiatric comorbidity of attentiondeficit/hyperactivity disorder in an adolescent Finnish population. J Am Acad Child Adolesc Psychiatry 46:1575-1583

85. Smith SM (2002) Fast robust automated brain extraction. Hum Brain Mapp 17:143-155

86. Starck T, Nikkinen J, Rahko J, Remes J, Hurtig T et al (2013) Resting state fMRI reveals a default mode dissociation between retrosplenial and medial prefrontal subnetworks in ASD despite motion scrubbing. Front Hum Neurosci 7:802

87. Stoet G, Snyder LH (2009) Neural correlates of executive control functions in the monkey. Trends Cogn Sci 13:228-234

88. Talairach J, Tournoux P (1988) Co-planar steretaxic atlas of the human brain. Thieme, Stuttgart
89. Tomasi D, Chang L, Caparellia EC, Ernst T (2007) Different activation patterns for working memory load and visual attention load. Brain Res 1132:158-165

90. Toyomaki A, Murohashi H (2013) "Salience network" dysfunction hypothesis in autism spectrum disorders. Jpn Psychol Res 55:175-185

91. Tzourio-Mazoyer N, Landeau B, Papathanassiou D, Crivello F, Etard $\mathrm{O}$ et al (2002) Automated anatomical labeling of activations in SPM using a macroscopic anatomical paracellation of the MNI MRI single-subject brain. Neuroimage 15:273-289

92. Uddin LQ, Menon V (2009) The anterior insula in autism: under-connected and under-examined. Neurosci Biobehav Rev 33:1198-1203

93. Uddin LQ, Supekar K, Lynch CJ, Khouzam A, Phillips J et al (2013) Salience network-based classification and prediction of symptom severity in children with autism. JAMA Psychiatry 70:869-879

94. Vuontela V, Steenari MR, Aronen ET, Korvenoja A, Aronen HJ et al (2009) Brain activation and deactivation during location and color working memory tasks in 11-13-year-old children. Brain Cogn 69:56-64

95. Wager TD, Jonides J, Reading S (2004) Neuroimaging studies of shifting attention: a meta-analysis. Neuroimage 22:16791693

96. Wang AT, Lee SS, Sigman M, Dapretto M (2007) Reading affect in the face and voice: neural correlates of interpreting communicative intent in children and adolescents with autism spectrum disorders. Arch Gen Psychiatry 64:698-708

97. Wechsler D (1991) Wechsler intelligence scale for children (WISC-III), 3rd edn. The Psychological Corporation, New York

98. Weiss LA, Arking DE (2009) A genome-wide linkage and association scan reveals novel loci for autism. Nature 461:802-808

99. Wheeler ME, Treisman AM (2002) Binding in short-term visual memory. J Exp Psychol Gen 131:48-64

100. Woolrich MW, Behrens TE, Beckmann CF, Jenkinson M, Smith SM (2004) Multilevel linear modelling for FMRI group analysis using Bayesian inference. Neuroimage 21:1732-1747

101. World Health Organisation (1994) The ICD-10 classification of mental and behavioural disorders. In: World Health Organisation (ed) Clinical descriptions and diagnostic guidelines. World Heath Organisation, Geneve 